\title{
A STUDY ON THE EFFECT OF VARIATION LOADS WITH DIFFERENT
}

\section{MATERIALS ON THE SPIRAL BEVEL GEARS}

\author{
JENAN MOHAMMED NAJE
}

Middle Technical University, Baghdad, Iraq

\begin{abstract}
Spiral bevel gear is typically adopted in high-speed mechanism components that transmit power and rotational motions amid dual intersecting shafts have (right angle axes). Therefore, because of the change in counterbalance, they may have slightly varies dynamic behaviour and gear mesh characteristics. Furthermore, the friction and lubrication effects may moreover play a significant character in its dynamic performances. The effect of variation loads with different materials on the spiral bevel gears have been analyzed and studied in this paper.

KEYWORDS: Spiral Bevel Gear, Loads Effect, Loads Analyses \& Material Durability
\end{abstract}

Received: Dec 16, 2018; Accepted: Jan 06, 2019; Published: Feb 02, 2019; Paper Id.: IJMPERDAPR20193

\section{INTRODUCTION}

Spiral Bevel Gears are commonly employed as a consequence of their suitability to transfer power between nonparallel shafts at any speed or angle. It has curved and slope gear teeth concerning the pitch cone surface [1].There are many indications that researchers have used in their laboratory experiments to study and analyze gears [2, 3, 4]. Through comparison between Spiral bevel gears and straight bevel gears (zerol), have supplementary overlapping tooth action, that generates a smoother gear mesh. This smooth power transmission for the gear teeth lessens vibration and noise that raise exponentially at upper velocities [5, 6]. Consequently, the spiral bevel gear ability for variation in the mechanical load direction, coupled with their capability in vibration and noise decrease, create them a major applicant for usage in industry, advanced machine tools, vehicles and airplanes. Many effective models have been proposed with the evolution and innovation of CFD technologies to calculate and construct the bevel gear[7, 8]. A special-resolution finite element-established, gear tooth contact analysis tool $[9,10]$ can be employed to accomplish 3D quasi-static loaded tooth contact investigation. The effectual gear mesh depiction is adopted in the dynamic analysis and can be produced from the projected load distributions within the tooth contact surface areas. Tsai and Hsu[11] estimated that, used a cup-shape grinder or milling cutter for industrial the spiral bevel gear arrangements. They have resulting meshing restraint equation of bevel gear arrangements having point contact characteristics. Also they arrange it to be a novel method for industrial spiral bevel gears and the main characteristic is that the spiral bevel gears have single axis motion and which can be controlled through the cutting process. R. Yakut et al. [12] examined the load capacity of PC/ABS spur gears and investigated the gear damage. The usability of PC/ABS composite plastic material as spur gear has been as well examined. The result shows that PC/ABS materials usage has a benefit in numerous manufacturing areas for the reason that such materials are robust in contradiction of air, flame, ultraviolet lights and holding lower moister than PA66 GFR 30materials.Litvin et al.[13] developed the local synthesis algorithm for design, industrial, stress investigation of spiral bevel gears. Their experimental work results were expected by decreasing noise levels, 
minus vibration and improved toughness. The enhanced spiral bevel gear was obtainable through improving the bearing contact as well as in the case of a parabolic function of transmission errors caused in the rising endurance limit of the gear drives. Pio et al. [14]investigated a novel technique for kinematic and power flow investigation of the bevel epicyclical gear train having gyroscopic difficulty. A new formula was assumed and substituted spur gear trains with bevel gears and the Willis equation are additional improved with new power ratio expressions and the equation was validated with bevel gears.

The finite element (FE) program for tooth contact analysis is used for gears modelling and analysis. As a result, an exact information of the gear geometry is required. For the purpose of the complex bevel gear geometry, industrialized simulations can beutilized in this subject[15].

In this manuscript Replacements of different composite materials of the gear under the different loading condition and also the model analysis have performed with the intention of determining the stress, strain, total deformation, Fatigue and expected durability under different loads for each material.

\section{APPLIED MATERIALS}

Structural Steel and Aluminium Alloy materials having an application in high power transmission system like a gearbox used in automobile industries. For this purpose 3-D model of the helical gear pair with particular transmission ratio, and comparing it with aluminum. It was made in SOLIDWORKS software and the ANSYS 19.0 fem based analysis software was used as the analysis tool to carry out the static structural analysis in order to determine the behavior of both materials (aluminum and steel).

\section{Parametric Solid Modeling of Helical Gear}

According to, the surface of the force acting, the direction and magnitude changes, Spiral bevel gear teeth has convex and concave sides. They differ depending upon which is the driver and which is the driven. Figure 1 shows the profile locations of right-hand and left-hand spiral teeth. In the case of the driving gear is convex, the driven gear profile should be concave [16].

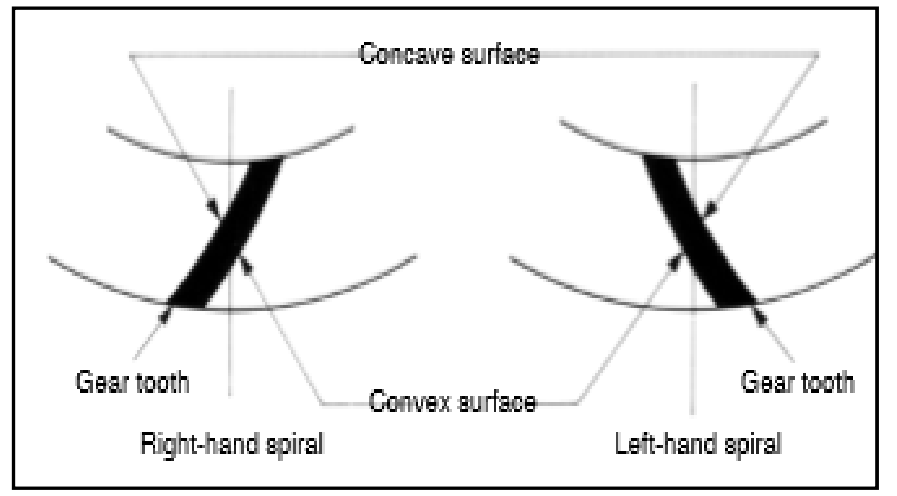

Figure 1: Convex and Concave Surfaces of a Spiral Bevel Gear

Torque used in a spiral bevel gear mesh stirs up tangential (circumferential), axil(thrust) and radial and separating loads on the gear teeth. [17]Namely, these loads are presumed to be applied point loads at the middle-point of the face width of the gear tooth. Separating and radial loads are reliant on the rotation direction and spiral hand along with pressure angle, spiral angle and pitch angle[18]. Figure 2 depicts the forces influence on the bevel gear. In order to start analysis, the 
initial step for investigating a bevel gear is to regulate the forces on the gear tooth midpoint.

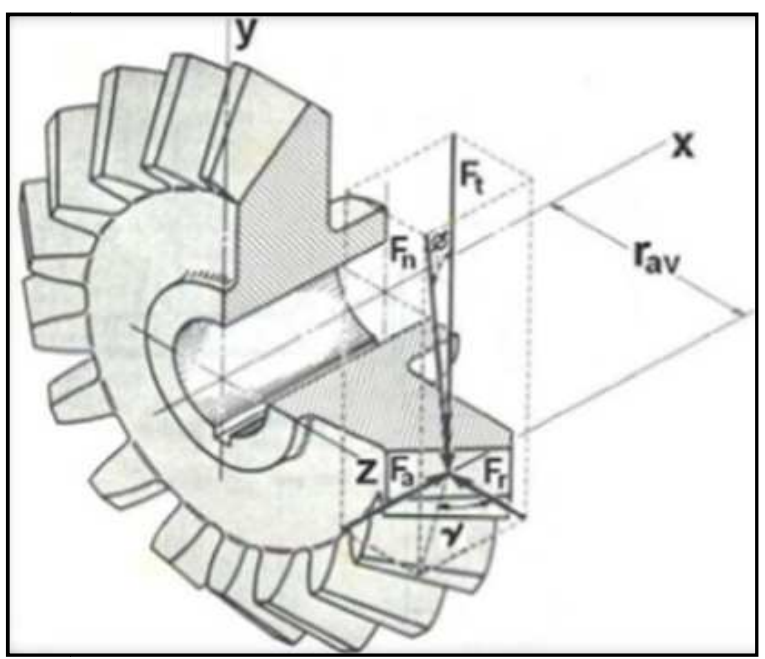

Figure 2: Force Analysis

After selecting the suitable design of spiral bevel gear, the model is built as shown in computer software section.

\section{COMPUTER SOFTWARE}

SOLIDWORKS and ANSYS 19.0 have used to design (Figure 3), analyze the results to give primarily indication of advantages and dis-advantages, and make a comparison with the experimental results.

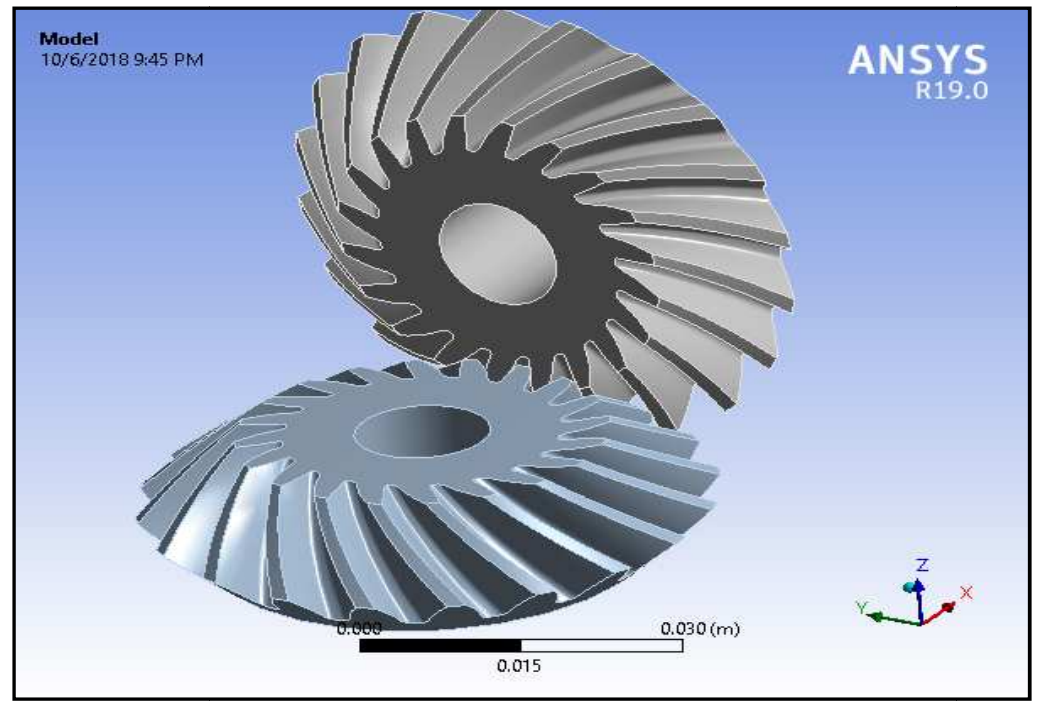

Figure 3: Ansys Image of the Built Spiral Bevel Gear

\section{Appling Mesh Type for the Model}

In this part, the model is cut into several small pieces to be analyzed for the identification of the stresses obtained conical gear and as in the image below, the mesh value is acceptable according to Skewness value that is near to 0. Figures below show the analytic process. 


\begin{tabular}{|l|l|}
\hline Quality \\
\hline Check Mesh Quality & Yes, Errors \\
\hline Error Limits & Standard Mechanical \\
\hline$\square$ Target Quality & Default $(0.050000)$ \\
\hline Smoothing & Medium \\
\hline Mesh Metric & Skewness \\
\hline$\square$ Min & 1.601 e-009 \\
\hline$\square$ Max & 0.9647 \\
\hline$\square$ Average & 0.22531 \\
\hline$\square$ Standard Deviation & 0.12222 \\
\hline
\end{tabular}

Figure 4: Creating New Material in Ansys-Workbench

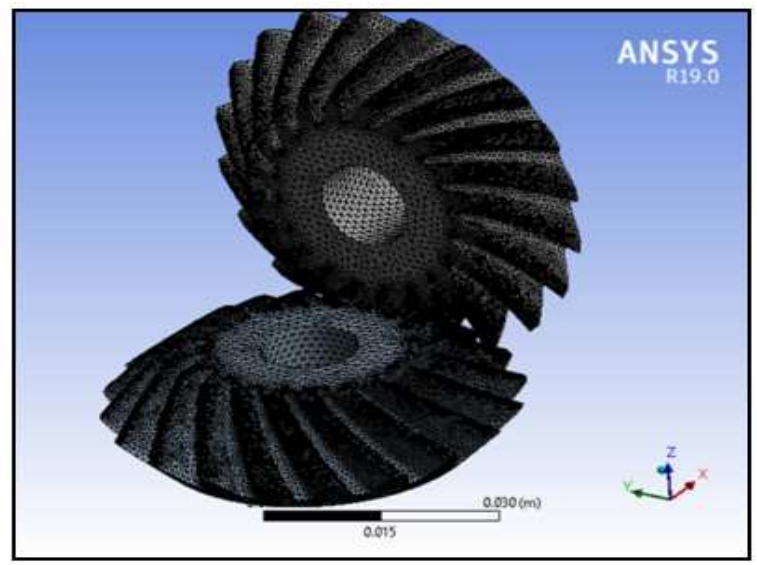

Figure 5: Mishing Modele Structure

The consequential gear mesh limitations involve the operative mesh point, line-of action, mesh stiffness, residual friction force path and friction constant. All that limitations are expected to differ with the variation in the contact regions such as the gear teeth mesh throughout the engagement sector. The time-variation performances of mesh parameters are uniform in the case of the dynamic analysis is completed with a constant insignificant gear rotating velocity.

In this model, the force attached to inclined teeth will be calculated as the mechanism will be connected by the shaft from the two sides of the spiral bevel gear. This will be expressed in the ansys package as fixed rotation. The torque is displayed and the variable is $(100,200,300,400$ and 500$) \mathrm{N} / \mathrm{m}$.

\section{ANSYS ANALYSIS IN STATIC STRUCTURAL AND SOLUTIONS}

\section{Aluminum Alloy}

For 100 N.mm Load, Model >Static Structural >Total Deformation is as illustrated in Figure 6 and Table 1.

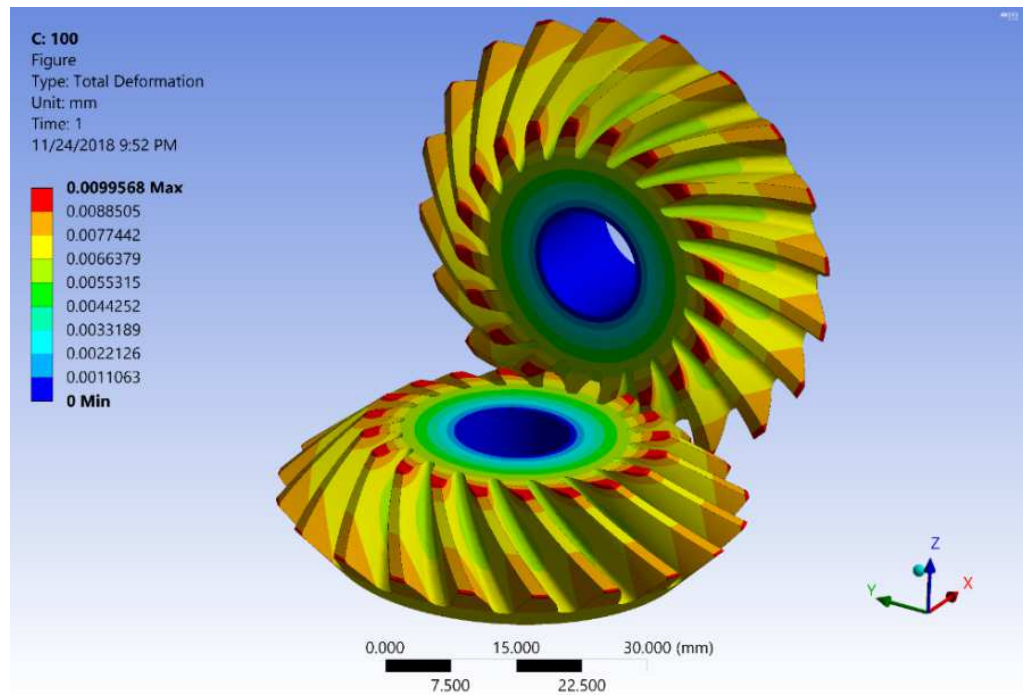

Figure 6: Model > Static Structural > Solution > Full Deformation

Table 1: Details of Model > Static Structural > Solution > Directional Deformation

\begin{tabular}{|c|c|c|c|}
\hline Time [s] & Minimum [mm] & Maximum [mm] & Average [mm] \\
\hline 1. & 0. & $9.9568 \mathrm{e}-003$ & $6.7697 \mathrm{e}-003$ \\
\hline
\end{tabular}


For Model >Static Structural >Resultant Elastic, the results are in Figure 7 and Table 2.

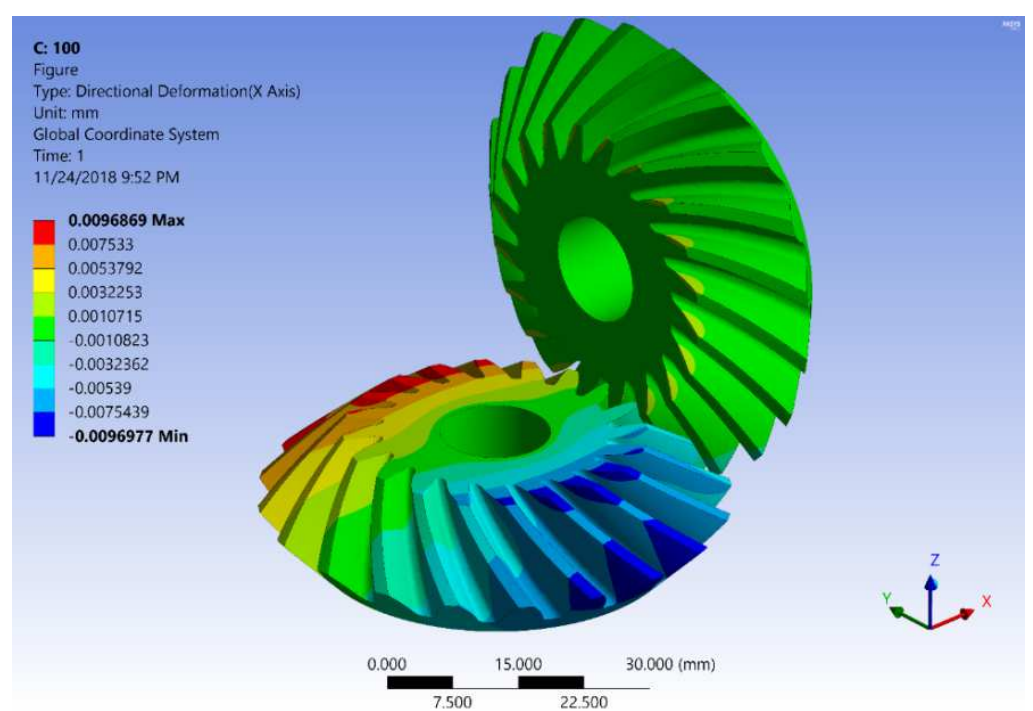

Figure 7: Model > Static Structural > Solution > Resultant Elastic Strain

Table 2: Details of Model > Static Structural > Solution > Resultant Elastic Strain

\begin{tabular}{|c|c|c|c|}
\hline Time [s] & Minimum [mm/mm] & Maximum [mm/mm] & Average $[\mathbf{m m} / \mathbf{m m}]$ \\
\hline 1. & $5.0049 \mathrm{e}-008$ & $3.1615 \mathrm{e}-003$ & $1.2843 \mathrm{e}-004$ \\
\hline
\end{tabular}

For Model $>$ Static Structural $>$ Solution $>$ Resultant Stress, the results are in Figure 8 and Table 3.

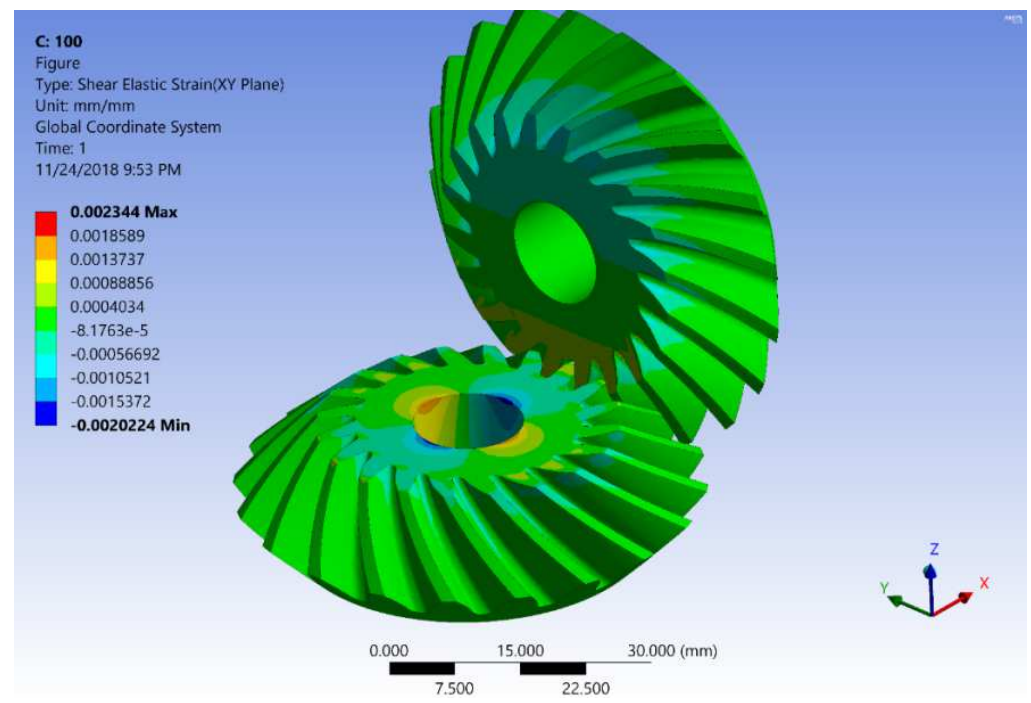

Figure 8: Model > Static Structural $>$ Solution > Resultant Stress

Table 3: Details of Model > Static Structural > Solution >Resultant Stress

\begin{tabular}{|c|c|c|c|}
\hline Time [s] & Minimum [MPa] & Maximum [MPa] & Average [MPa] \\
\hline 1. & $1.5279 \mathrm{e}-003$ & 199.54 & 8.9725 \\
\hline
\end{tabular}


For Model $>$ Static Structural $>$ Solution $>$ Fatigue Tool $>$ Damage, the results are in Figure 9 and Table 4.

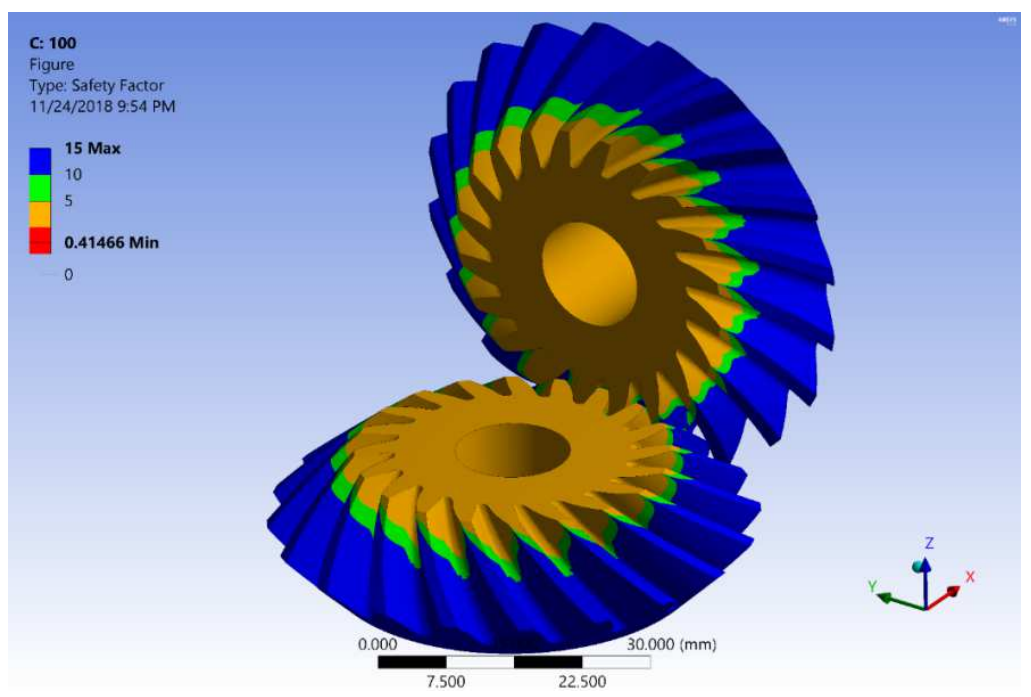

Figure 9: Model > Static Structural > Solution > Fatigue Tool > Damage

Table 4: Details of Model > Static Structural > Solution > Fatigue Tool > Damage

\begin{tabular}{|c|c|c|c|}
\hline Time [s] & Minimum & Maximum & Average \\
\hline 1. & 10. & 21815 & 10.061 \\
\hline
\end{tabular}

For 500 N.mm Load, Model > Static Structural > Solution >Total Deformation is as shown in Figure 10 and Table 5.

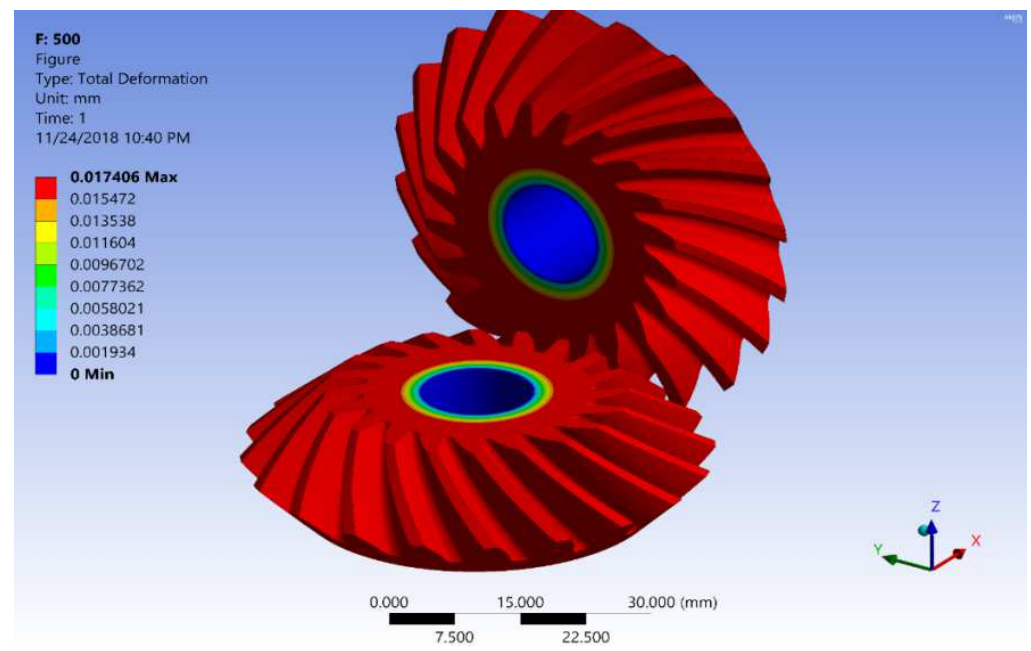

Figure 10: Model > Static Structural > Solution >Full Deformation

Table 5: Details of Model (F4) > Static Structural (F5) > Solution (F6) > Directional Deformation

\begin{tabular}{|c|c|c|c|}
\hline Time [s] & Minimum [mm] & Maximum [mm] & Average [mm] \\
\hline 1. & 0. & $4.9784 \mathrm{e}-002$ & $3.3849 \mathrm{e}-002$ \\
\hline
\end{tabular}


For Model $>$ Static Structural $>$ Solution $>$ Resultant Elastic Strain, the results are in Figure 11 and Table 6.

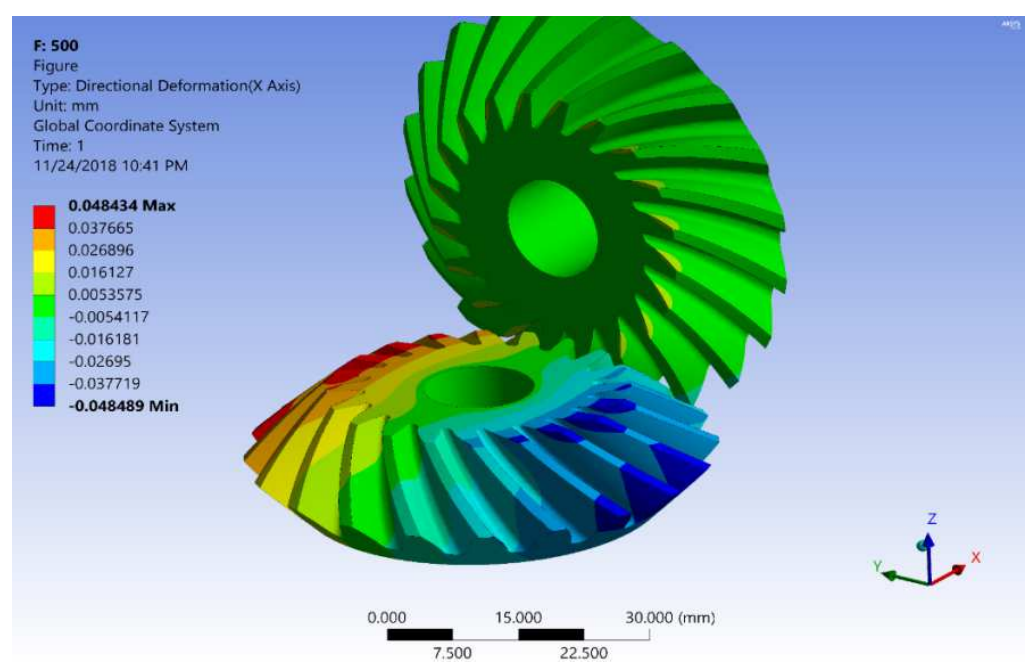

Figure 11: Model > Static Structural > Solution > Resultant Elastic Strain

Table 6: Details of Model > Static Structural > Solution > Resultant Elastic Strain

\begin{tabular}{|c|c|c|c|}
\hline Time [s] & Minimum [mm/mm] & Maximum [mm/mm] & Average [mm/mm] \\
\hline 1. & $2.5025 \mathrm{e}-007$ & $1.5808 \mathrm{e}-002$ & $6.4216 \mathrm{e}-004$ \\
\hline
\end{tabular}

For Model $>$ Static Structural $>$ Solution >Resultant Stress, the results are in Figure 12 and Table 7.

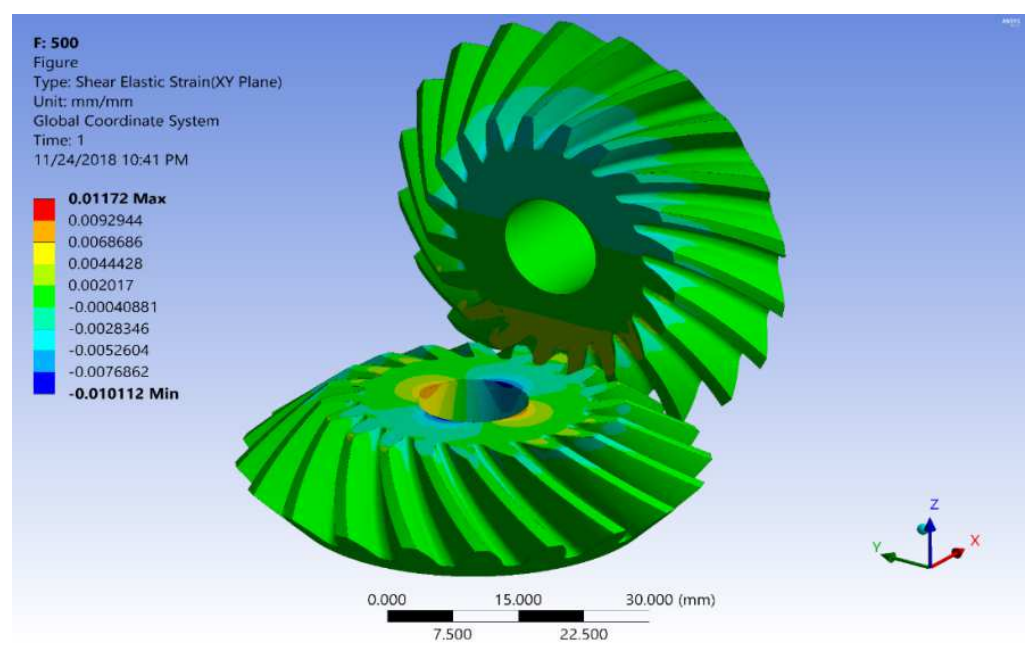

Figure 12: Model > Static Structural $>$ Solution > Resultant Stress

Table 7: Details of Model > Static Structural > Solution > Resultant Stress

\begin{tabular}{|c|c|c|c|}
\hline Time [s] & Minimum [MPa] & Maximum [MPa] & Average [MPa] \\
\hline 1. & $7.6396 \mathrm{e}-003$ & 997.69 & 44.863 \\
\hline
\end{tabular}


For Model $>$ Static Structural $>$ Solution $>$ Fatigue Tool $>$ Damage, the results are in Figure 13 and Table 8.

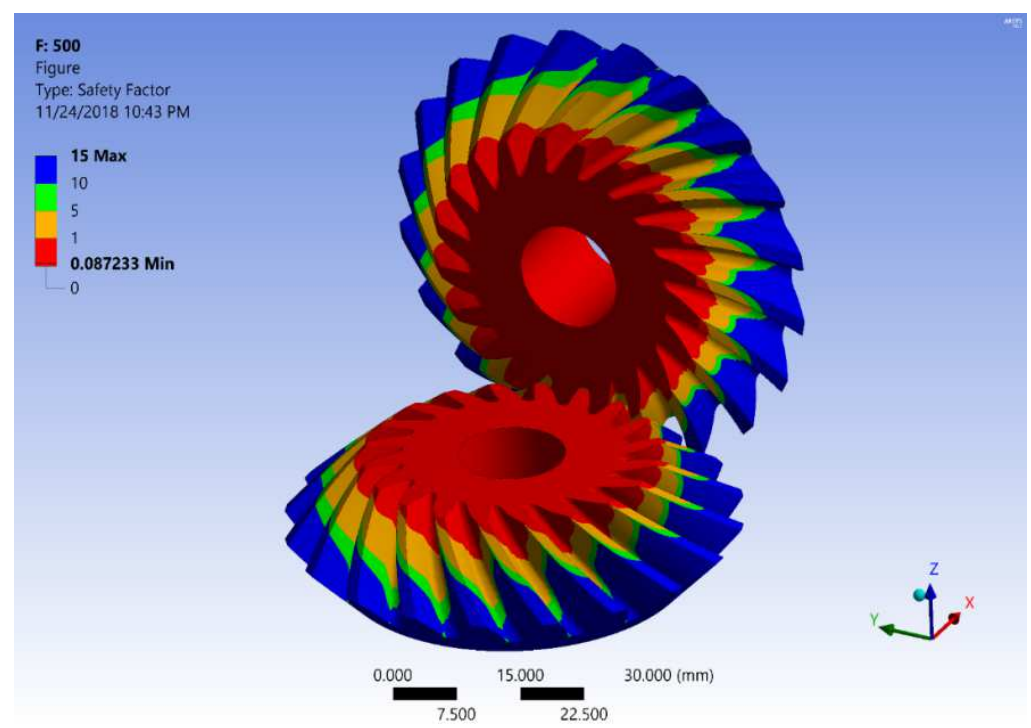

Figure 13

Model $>$ Static Structural $>$ Solution $>$ Fatigue Tool $>$ Damage

Table 8: Details of Model > Static Structural $>$ Solution $>$ Fatigue Tool $>$ Damage

\begin{tabular}{|c|c|c|c|}
\hline Time [s] & Minimum & Maximum & Average \\
\hline 1. & 10. & $1 . e+032$ & $1.5852 \mathrm{e}+029$ \\
\hline
\end{tabular}

The output of Constant Amplitude Load Fully Reversed in the case of Model > Static Structural > Solution > Fatigue Tool is shown in Figure 14. Figure 15 shows Mean stress correction theory in the case of Model > Static Structural $>$ Solution > Fatigue Tool > Results.

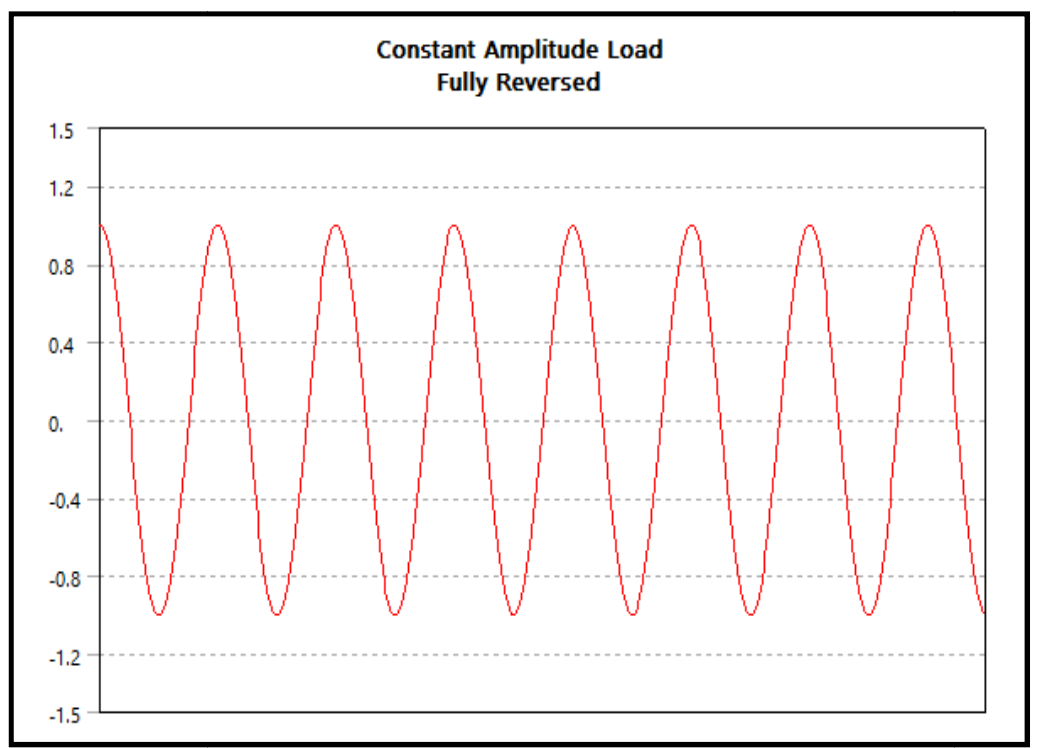

Figure 14: Constant Amplitude Load Fully Reversed, Model > Static Structural $>$ Solution $>$ Fatigue Tool 


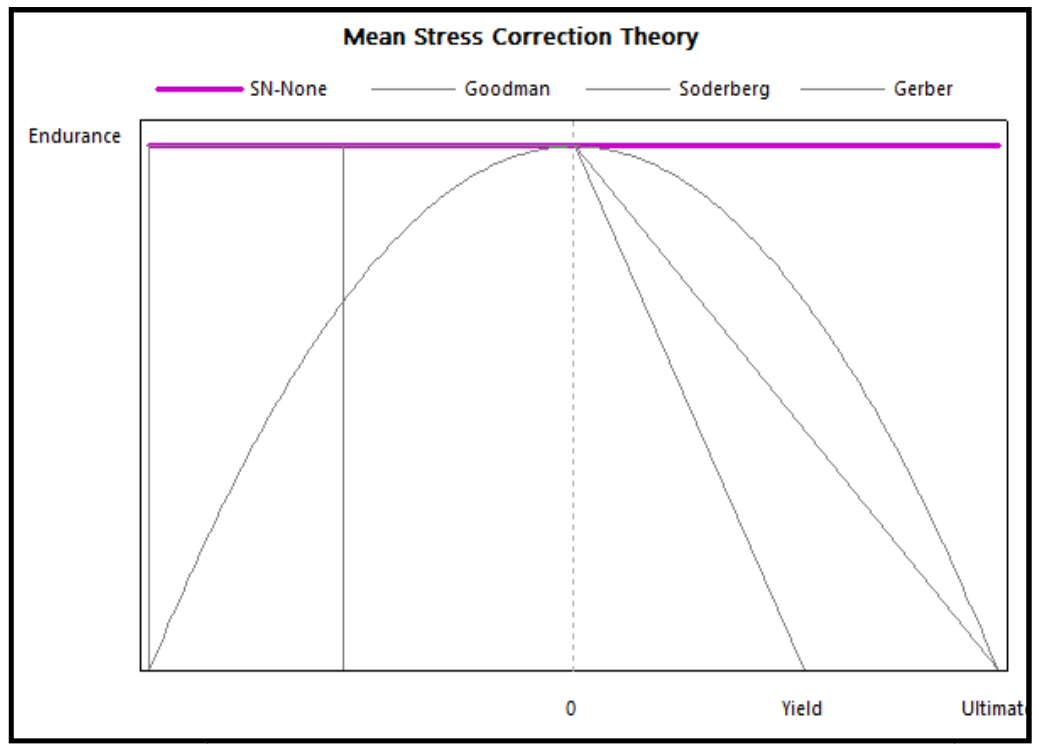

Figure 15: Mean Stress Correction Theory, Model $>$ Static Structural $>$ Solution $>$ Fatigue Tool $>$ Results

\section{Structural Steel}

For 100 N.mm Load, Model >Static Structural > Total Deformation as illustrated in Figure 16 and Table 9.

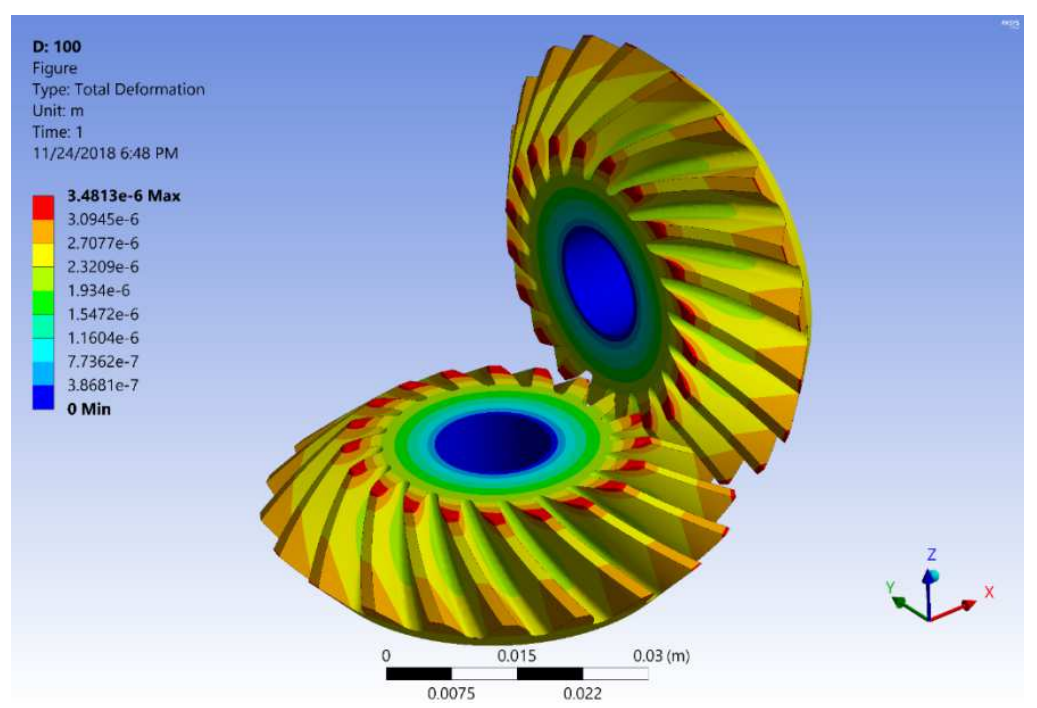

Figure 16: Model >Static Structural > Total Deformation

Table 9: Details of Model >Static Structural > Total Deformation

\begin{tabular}{|c|c|c|c|}
\hline Time [s] & Minimum [m] & Maximum [m] & Average [m] \\
\hline 1. & 0. & $3.4813 \mathrm{e}-006$ & $2.3528 \mathrm{e}-006$ \\
\hline
\end{tabular}


For Model $>$ Static Structural > Solution > Resultant Elastic Strain, the results are inFigure 17 and Table 10.

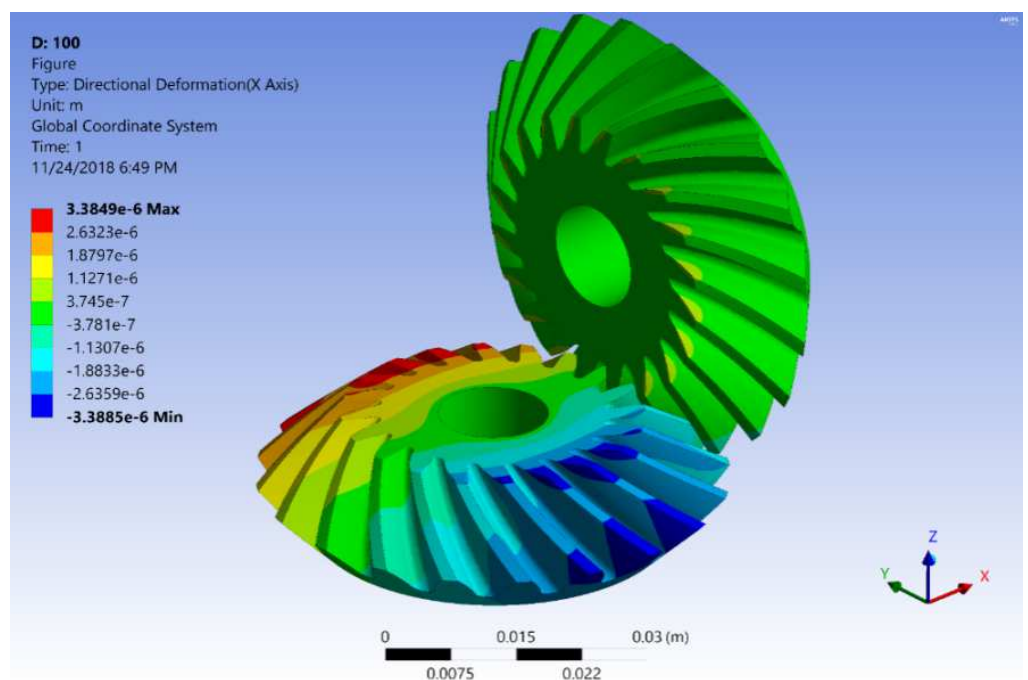

Figure 17: Model > Static Structural > Solution > Resultant Elastic Strain

Table 10: Details of Model > Static Structural > Solution > Resultant Elastic Strain

\begin{tabular}{|c|c|c|c|}
\hline Time [s] & Minimum [m/m] & Maximum [m/m] & Average $[\mathrm{m} / \mathbf{m}]$ \\
\hline 1. & $1.8758 \mathrm{e}-008$ & $1.1142 \mathrm{e}-003$ & $4.5543 \mathrm{e}-005$ \\
\hline
\end{tabular}

For Model $>$ Static Structural $>$ Solution $>$ Resultant Stress, the results are in Figure 18 and Table 11.

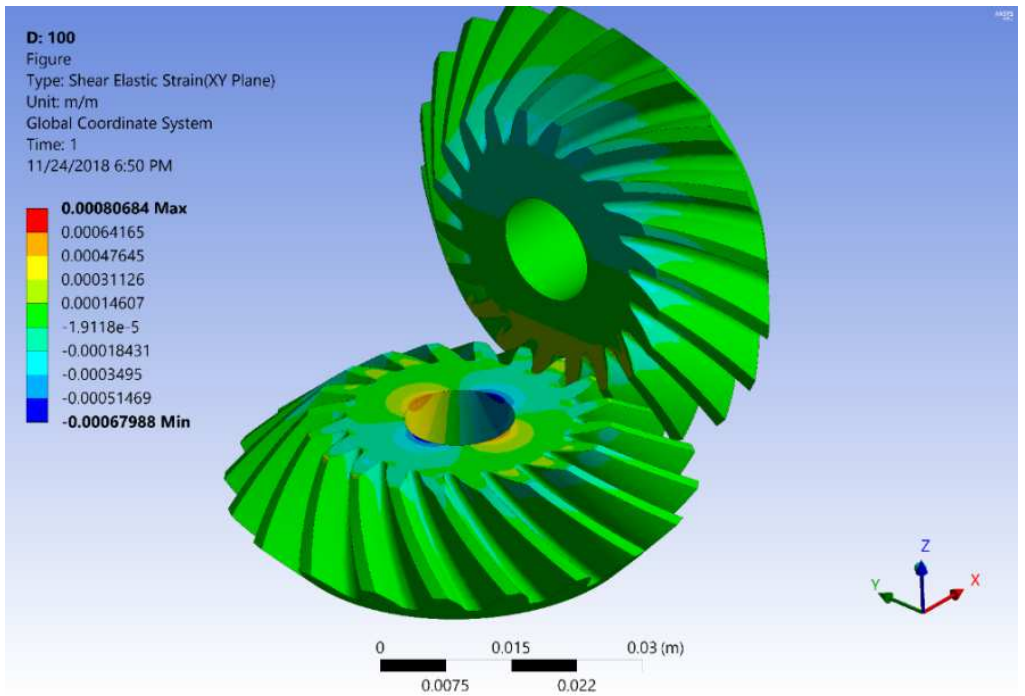

Figure 18: Model > Static Structural $>$ Solution > Resultant Stress

Table 11: Details of Model $>$ Static Structural $>$ Solution $>$ Resultant Stress

\begin{tabular}{|c|c|c|c|}
\hline Time [s] & Minimum [Pa] & Maximum [Pa] & Average [Pa] \\
\hline 1. & 1723.7 & $1.9763 \mathrm{e}+008$ & $8.9619 \mathrm{e}+006$ \\
\hline
\end{tabular}


For Model $>$ Static Structural $>$ Solution > Fatigue Tool $>$ Damage, the results are in Figure 19 and Table 12.

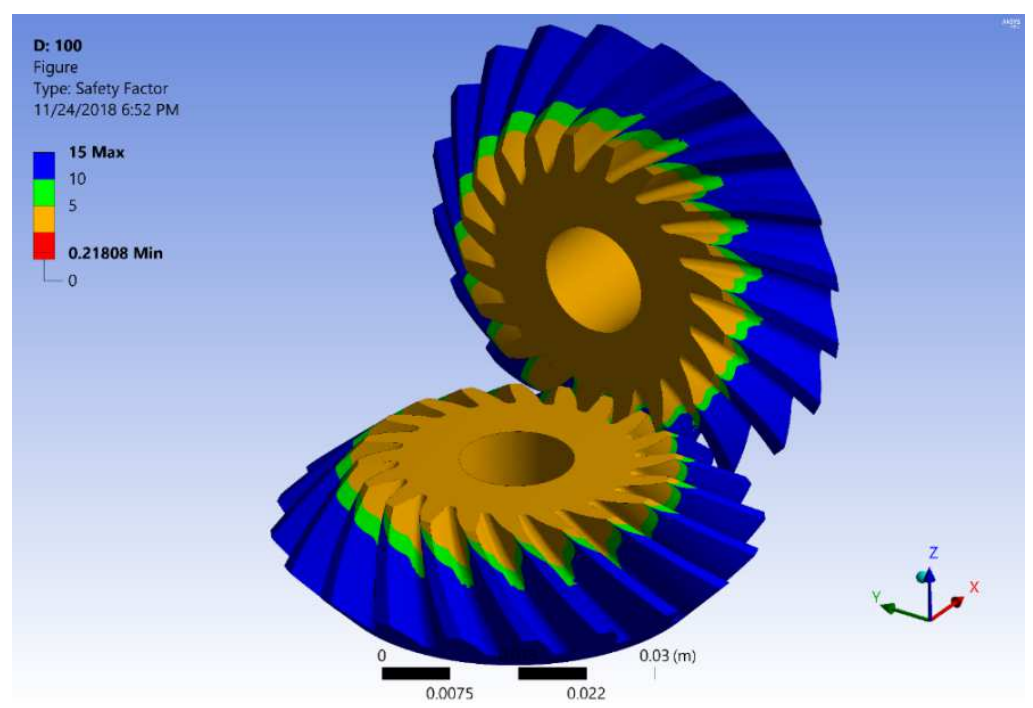

Figure 19: Model > Static Structural > Solution > Fatigue Tool $>$ Damage

Table 12: Details of Model > Static Structural $>$ Solution $>$ Fatigue Tool $>$ Damage

\begin{tabular}{|c|c|c|c|}
\hline Time [s] & Minimum & Maximum & Average \\
\hline 1. & 1000. & 37341 & 1000.3 \\
\hline
\end{tabular}

For 500 N.mm Load, Model > Static Structural > Total Deformation as illustrated in Figure 20 and Table 13.

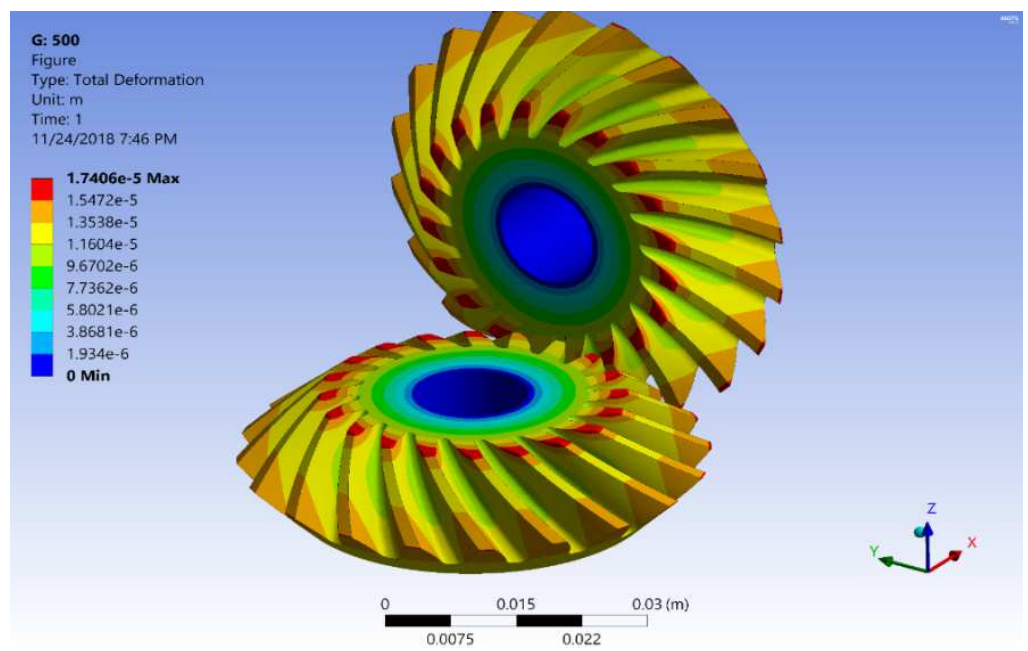

Figure 20: Model >Static Structural > Total Deformation

Table 13: Details of Model > Static Structural > Total Deformation

\begin{tabular}{|c|c|c|c|}
\hline Time [s] & Minimum [m] & Maximum [m] & Average [m] \\
\hline 1. & 0. & $1.7406 \mathrm{e}-005$ & $1.1764 \mathrm{e}-005$ \\
\hline
\end{tabular}


For Model $>$ Static Structural > Solution >Resultant Elastic Strain, the results are in Figure 21 and Table 14.

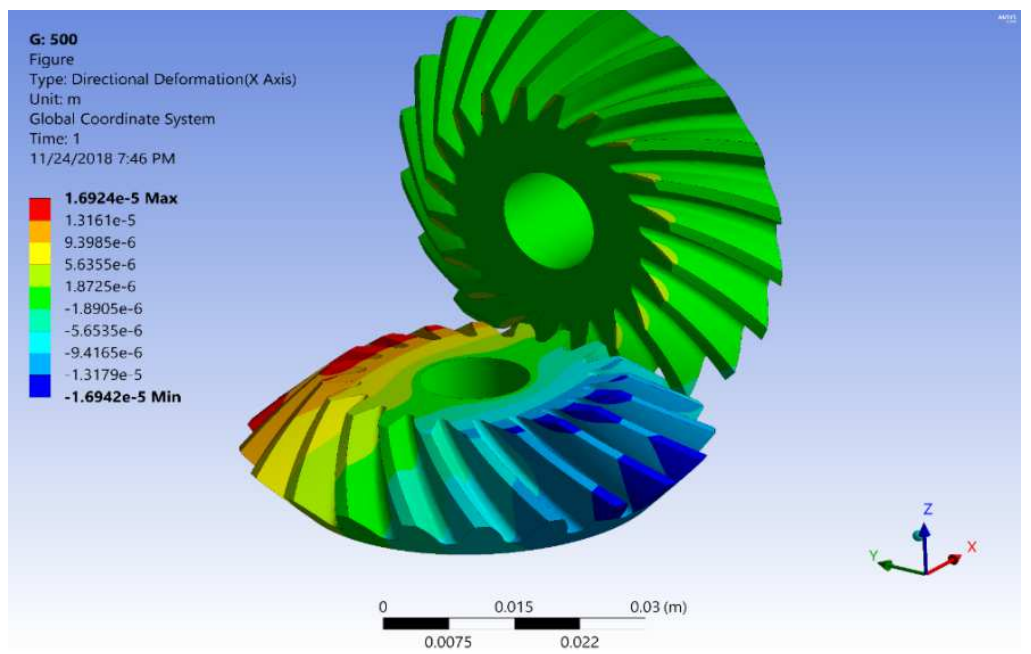

Figure 21: Model > Static Structural > Solution > Resultant Elastic Strain

Table 14: Details of Model > Static Structural > Solution > Resultant Elastic Strain

\begin{tabular}{|c|c|c|c|}
\hline Time [s] & Minimum $[\mathbf{m} / \mathbf{m}]$ & Maximum $[\mathbf{m} / \mathbf{m}]$ & Average $[\mathbf{m} / \mathbf{m}]$ \\
\hline 1. & $9.379 \mathrm{e}-008$ & $5.5712 \mathrm{e}-003$ & $2.2772 \mathrm{e}-004$ \\
\hline
\end{tabular}

For Model > Static Structural > Solution > Resultant Stress, the results are depicted in Figure 22 and Table 15.

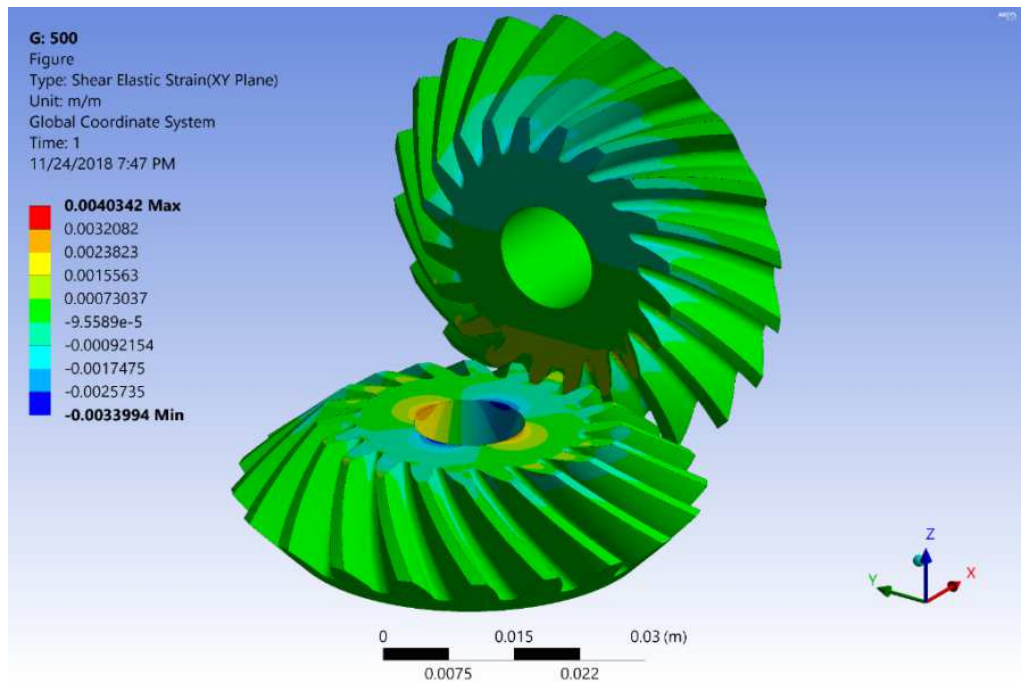

Figure 22: Model $>$ Static Structural $>$ Solution > Resultant Stress

Table 15: Details of Model $>$ Static Structural $>$ Solution $>$ Resultant Stress

\begin{tabular}{|c|c|c|c|}
\hline Time [s] & Minimum [Pa] & Maximum [Pa] & Average [Pa] \\
\hline 1. & 8618.5 & $9.8815 \mathrm{e}+008$ & $4.4809 \mathrm{e}+007$ \\
\hline
\end{tabular}


For Model $>$ Static Structural $>$ Solution > Fatigue Tool $>$ Damage, the results are depicted in Figure 23 and Table 16.

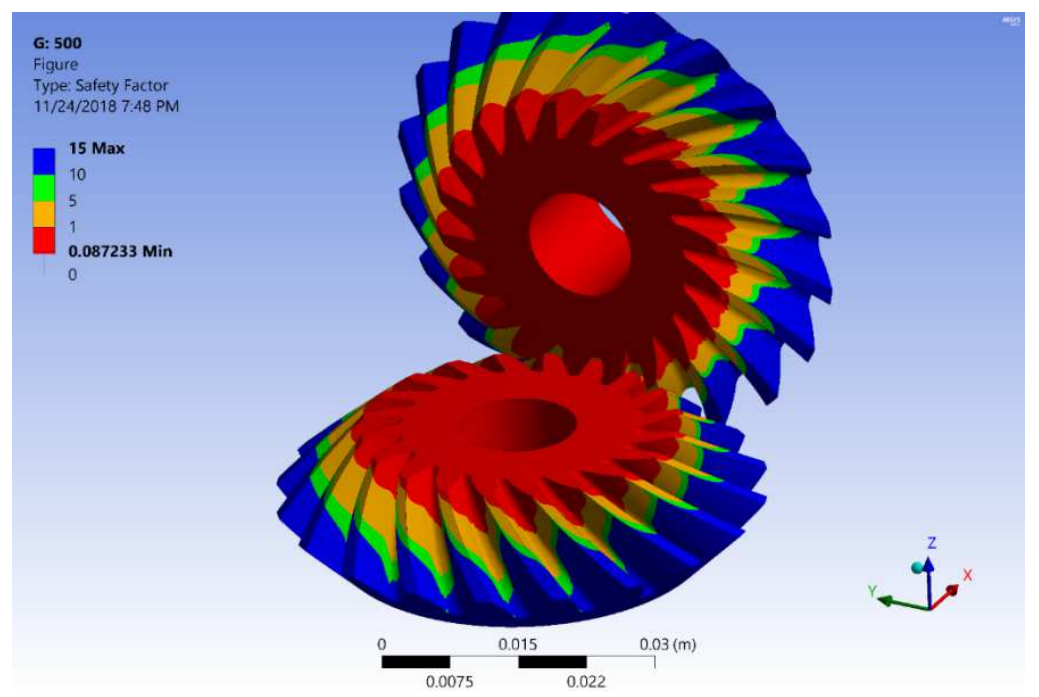

Figure 23: Model > Static Structural $>$ Solution > Fatigue Tool $>$ Damage

Table 16: Details of Model $>$ Static Structural $>$ Solution $>$ Fatigue Tool $>$ Damage

\begin{tabular}{|c|c|c|c|}
\hline Time [s] & Minimum & Maximum & Average \\
\hline 1. & 1000. & $4.0753 \mathrm{e}+006$ & 3277.5 \\
\hline
\end{tabular}

The output of Constant Amplitude Load Fully Reversed in the case of Model > Static Structural > Solution > Fatigue Tool is shown in Figure 24. Figure 25 shows Mean stress correction theory in the case of Model > Static Structural $>$ Solution > Fatigue Tool > Results.

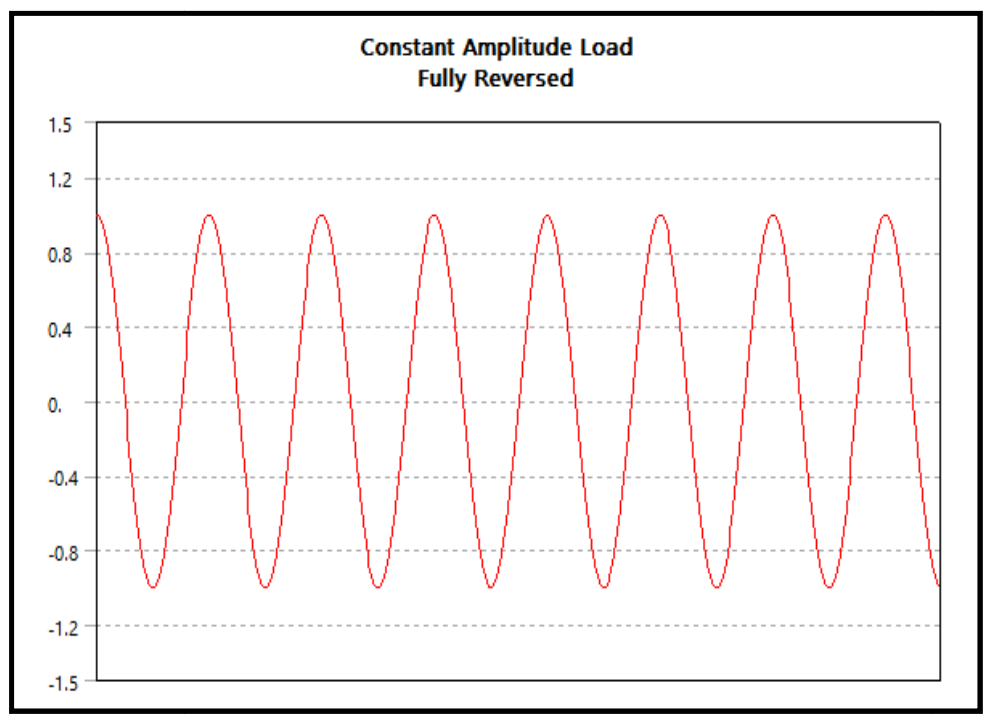

Figure 24: Constant Amplitude Load Fully Reversed, Model > Static Structural > Solution > Fatigue Tool 


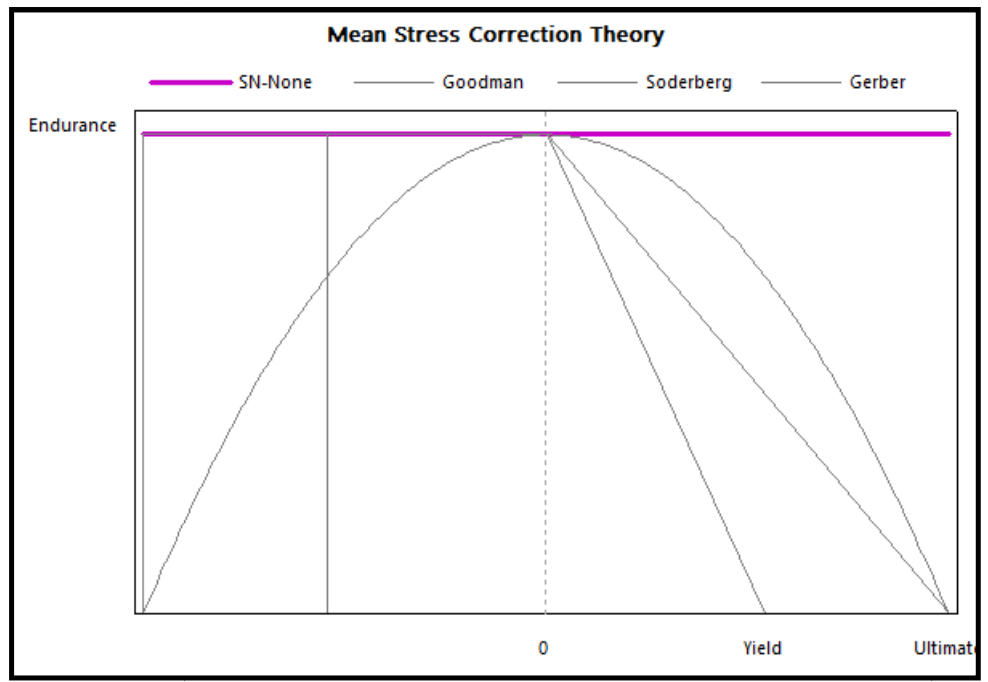

Figure 25: Mean Stress Correction Theory, Model $>$ Static Structural $>$ Solution $>$ Fatigue Tool $>$ Results

\section{RESULTS AND DISCUSSION}

Results are classified to realize the total deformation difference between the Structural Steel and Aluminum Alloy with respect to load as shown in Figure 26 and Figure 29. Also, results are shown for Shear Stress between Structural Steel and Aluminum Alloy with respect to load as depicted in Figures 27, 28, 30, and 31 to calculate the durability and to organize the Structural Steel and Aluminum Alloy uses in Spiral Bevel Gears. Accordingly, based on above figures, the Structural Steel is appropriate to be used in Spiral Bevel Gears as it has corrosion and erosion resistance with high mechanical features. Aluminium Alloy is suitable to be used for light weight purposes, having good thermal conductivity, anti-corrosion.

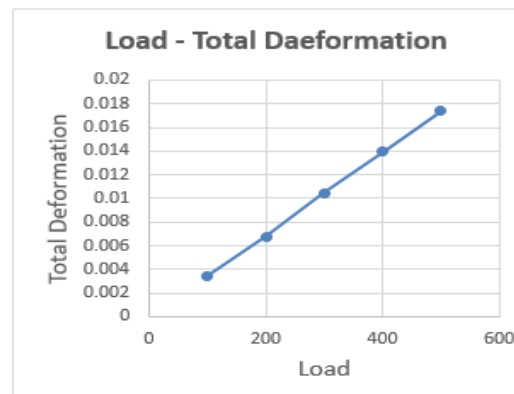

\begin{tabular}{|c|c|}
\hline Load & Total Deformation \\
\hline 100 & 0.0034813 \\
\hline 200 & 0.0067892 \\
\hline 300 & 0.010444 \\
\hline 400 & 0.013925 \\
\hline 500 & 0.017406 \\
\hline
\end{tabular}

Figure 26: Total Deformation between Structural Steel and Load
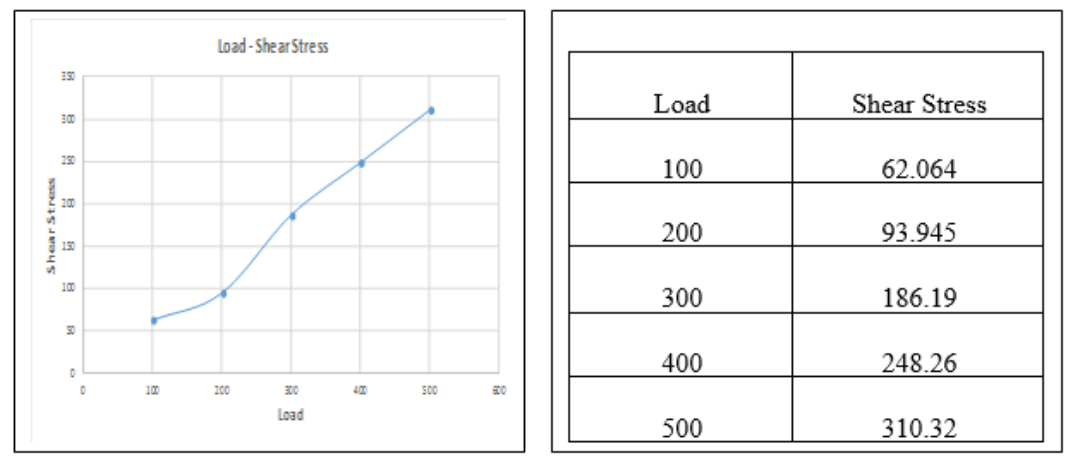

Figure 27: Shear Stress between Structural Steel and Load 


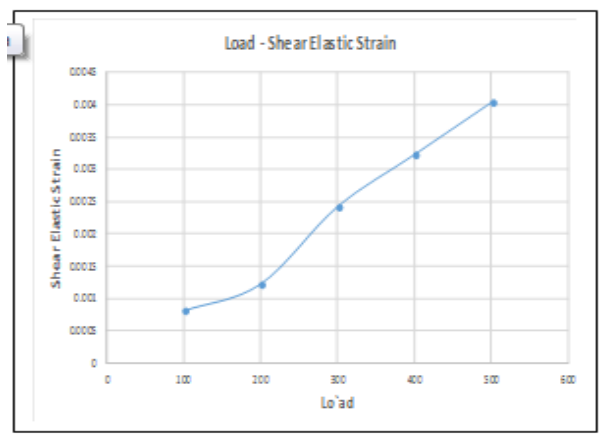

\begin{tabular}{|c|c|}
\hline \multicolumn{2}{|c|}{} \\
\hline Load & Shear Elastic Strain \\
\hline 100 & 0.00080684 \\
\hline 200 & 0.0012213 \\
\hline 300 & 0.0024205 \\
\hline 400 & 0.0032273 \\
\hline 500 & 0.0040342 \\
\hline
\end{tabular}

Figure 28: Shear Elastic Strain between Structural Steel and Load

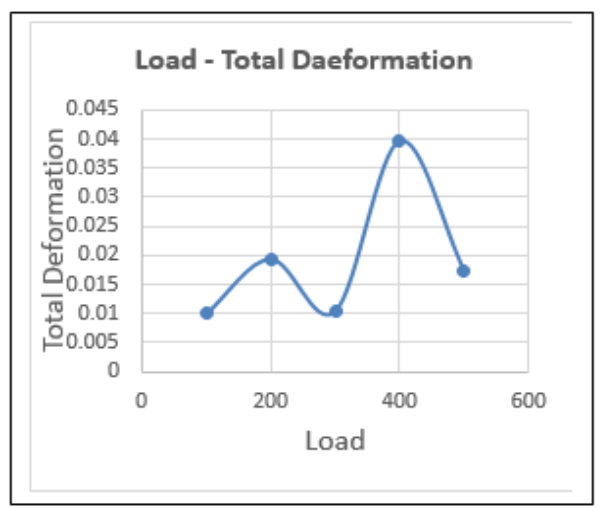

\begin{tabular}{|c|c|}
\hline \multicolumn{2}{|c|}{} \\
\hline Load & Total Deformation \\
\hline 100 & 0.0099568 \\
\hline 200 & 0.019452 \\
\hline 300 & 0.010444 \\
\hline 400 & 0.039827 \\
\hline 500 & 0.017406 \\
\hline
\end{tabular}

Figure 29: Total Deformation between Aluminum Alloy and Load

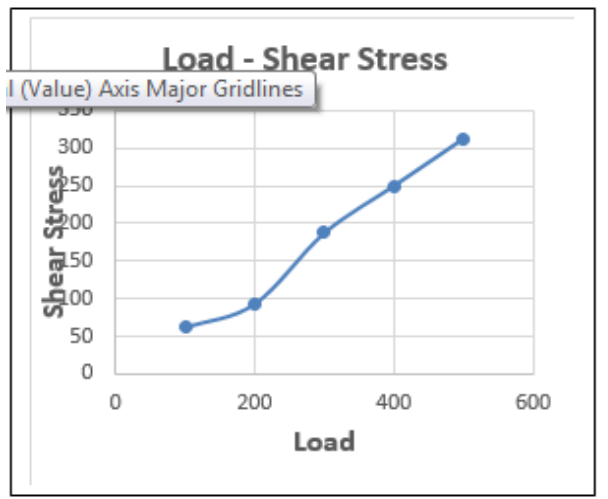

\begin{tabular}{|c|c|}
\hline \multicolumn{2}{|c|}{} \\
\hline Load & Shear Stress \\
\hline 100 & 62.566 \\
\hline 200 & 93.822 \\
\hline 300 & 187.7 \\
\hline 400 & 250.27 \\
\hline 500 & 312.83 \\
\hline
\end{tabular}

Figure 30: Shear Stress between Aluminum Alloy and Load

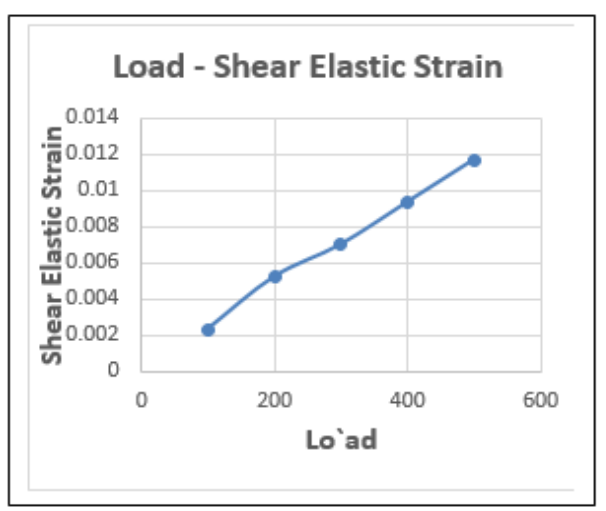

\begin{tabular}{|c|c|}
\hline \multicolumn{2}{|c|}{} \\
\hline Load & Shear Elastic Strain \\
\hline 100 & 0.002344 \\
\hline 200 & 0.005248 \\
\hline 300 & 0.0070321 \\
\hline 400 & 0.0093762 \\
\hline 500 & 0.01172 \\
\hline
\end{tabular}

Figure 31: Shear Elastic Strain between Aluminum Alloy and Load 


\section{CONCLUSIONS}

Theoretical study has been carried out to estimate the performance of Spiral Bevel Gears, and to choose suitable metal according to the working procedure.

The Structural Steel is proper to be used in Spiral Bevel Gears since it has corrosion and erosion resistant, with high mechanical properties (hardness, bending and impact resistance).

Aluminium Alloy suitable to be used for light weight purposes, having good thermal conductivity, anti-corrosion.

\section{REFERENCES}

1. Radescu.G.H, Designing guideline for machine construcing, BUCHAREST: 13 DECEMBRIE 1918, 1986.

2. Fangyan Zheng, Xiaodong Guo, Mingde Zhang, Weiqing Zhang, "Research on the mold release motion for spiral bevel gear," Mechanical Sciences, vol. Volume 136, pp. 482-492, 2018.

3. K.-D. Bouzakis, W. Konig, K.Vossen, "Use of Powder Metallurgical High Speed Steel in Gear Hobbing and Gear Shaping," CIRP Annals- ELSEVIER, vol. Volume 31, pp. 25-29, 1982.

4. Avishkar Bhoskar, Sanjay Yadav, "DESIGN OF BEVEL GEAR PAIR FOR GATE VALVE," International Journal of Research in Engineering and Technology, vol. 05, no. 12, 2016.

5. M. D. Brown, Design and Analysis of a Spiral Bevel Gear, 2009.

6. Changjiang Zhou, Zuodong Li, Bo Hu, Haifei Zhan, Xu Han, "Analytical Solution to Bending and Contact Strength of Spiral Bevel Gears in Consideration of Friction," International Journal of Mechanical Sciences- ELSEVIER, vol. 128-129, pp. 475485, 2017.

7. Mohit Singh, Waris Khan, Sanjeev Kumar, "STRUCTURAL ANALYSIS OF COMPOSITE MATERIAL HELICAL GEAR UNDER," INTERNATIONAL JOURNAL OF ENGINEERING SCIENCES \& RESEARCH TECHNOLOGY, vol. 3.00, pp. 22779655, 2016.

8. Sylvain Pallas, Yann Marchesse, Christophe Changenet, Fabrice Ville, Philippe Velex, "Application and validation of a simplified numerical approach for the," Computers \& Fluids-ELSEVIER, vol. 84, p. 39-45, 2013.

9. Sinha, A., \& Farhat, Z. (2014). A study of porosity effect on tribological behavior of cast Al A380M and sintered Al 6061 alloys. Journal of Surface Engineered Materials and Advanced Technology, 5(01), 1.

10. R. Li, C. Huang, "Tooth contact finite element analysis of spiral bevel and hypoid gears," Chinese Journal of Mechanical Engineering, pp. 82-86, 1995.

11. Zhiheng Feng, Shilong Wang, Teik C. Lim, Tao Peng, "Enhanced friction model for high-speed right-angle gear dynamics," Journal of Mechanical Science and Technology, vol. 25 (11), pp. 2741-2753, 2011.

12. Ying-Chien Tsai, Wei-Yi Hsu," The study on the design of spiral bevel gear sets with circular-arc contact paths and tooth profiles," Mechanism and Machine Theory- ELSEVIER, vol. 43, no. 9, pp. 1158-1174, 2008.

13. R. Yakut, H. Duzcukoglu, M. T. Demirci, "The load capacity of PC/ABS spur gears and investigation of," Archives of Materials science and Engineering, November, pp. 41-46, 2009.

14. Faydor L. Litvin, Alfonso Fuentes, Kenichi Hayasaka, "Design, manufacture, stress analysis, and experimental tests of lownoise high endurance spiral bevel gears, "Mechanism and Machine Theory- ELSEVIER, vol. 41, pp. 83-118, 2006. 
15. Mahadeshwar, A. M., Ghonge, A. S., \& Chaudhari, K. A. Design, Development And Analysis Of Differential Anti-Reverse Mechanism.

16. Germano Del Pio, Ettore Pennestrì, Pier Paolo Valentini, "Kinematic and power-flow analysis of bevel gears planetary gear trains with gyroscopic complexity," Mechanism and Machine Theory- ELSEVIER, vol. 70, pp. 523-537, 2013.

17. hristian Brecher, Christoph Löpenhaus, Peter Knecht, "Design of Acoustical Optimized Bevel Gears Using Manufacturing Simulation," Procedia CIRP- ELSEVIER, vol. 41, pp. 902-907, 2016.

18. Bryan Blakey, Luke Rust, Brian Chamberlin, "Bevel Gear Analysis," University of Idah, 2008.

19. Aref Bahrami Ghahnavieh, Saleh Akbarzadeh, Peiman Mosaddegh, "A numerical study on the performance of straight bevel gears operating under mixed lubrication regime, "Mechanism and Machine Theory-ELSEVIER, vol. 75, p. 27-40, 2014.

20. Santosh S Bagewadi, I G Bhavi, S N Kurbet, "Design And Analysis Of Crown Pinion Of A Differential Gear Box For Reduced Number Of Teeth To Improve Torque Transmitted," International Journal of Mechanical Engineering and Robotics Research, vol. 3, p. $2278-0149,2014$. 
